\title{
O Uso das TICs e da Pesquisa como Recursos Pedagógicos no Ensino de Bioquímica para o Curso de Licenciatura em Química
}

\author{
Emmanuela Ferreira de Lima \\ Instituto Federal Goiano, campus Morrinhos \\ * Autora para correspondência: emmanuela.lima@ifgoiano.edu.br
}

\begin{abstract}
RESUMO
Com a chegada da tecnologia, o uso de computadores, tablets e celulares do tipo smartphomes tem aumentado a cada dia, e a sociedade vem se adequando a essas mudanças em todas as áreas do conhecimento, e não poderia ser diferente no ensino. As Tecnologias da Informação e Comunicação (TICs) vêm se tornando uma ferramenta importante de auxílio na aprendizagem, podendo conferir dinamismo às aulas e despertar o interesse dos alunos também no ensino de nível superior. Aliada às TICs, a pesquisa proporciona uma participação ativa do aluno na busca pelo conhecimento e o auxilia em seu crescimento intelectual e pessoal, dando mais autonomia e confiança na abordagem de determinados conteúdos. Este trabalho tem como objetivo relatar a experiência vivida na disciplina de Bioquímica pertencente ao sétimo período do curso de Licenciatura em Química do Instituto Federal Goiano, campus Morrinhos, Goiás, no que diz respeito ao uso de programas de computador e da pesquisa como ferramentas no estudo do tema proteínas. Os resultados obtidos foram bastante positivos, mostrando que as TICs, associadas à pesquisa, no ensino superior de Química e Bioquímica, podem ser usadas como uma alternativa para aprimorar metodologias de ensino e, por sua vez, melhorar o aprendizado dos alunos.
\end{abstract}

Palavras-Chave: TIC; Metodologia de Ensino; Ensino de Bioquímica; Pesquisa.

\begin{abstract}
With the advent of the technology, the use of notebooks, tablets and smartphones has increased every day and the society has been adapting itself to these changes in all areas of knowledge and it could not be different in teaching. The Information and Communication Technologies (ICTs) have become an important tool of aid in the learning, being able to give dynamism to the classes and to arouse the interest of the students also in higher education as well. Associated to ICTs, this research provides an active participation of the students in the search for knowledge, helping in their intellectual and personal growth, giving more autonomy and confidence in the approach of certain contents. The objective of this work is to report the experience in the discipline of Biochemistry that belongs to the seventh period of the Chemistry degree of the Instituto Federal Goiano, campus Morrinhos, Goiás, regarding the use of computer programs and research as tools in the study of the proteins. The results obtained were very positive, showing that ICT, associated with research in higher Chemistry and Biochemistry education can be used as an alternative to improve teaching methodologies and student learning.
\end{abstract}

Keywords: Information and Communication Technologies (ICT); Teaching Methodology; Biochemistry Teaching; Research

O mundo está na era da Tecnologia da Informação e Comunicação (TIC), em que a informação, o ensino e a aprendizagem não se restringem mais ao tempo e ao espaço. Ensinar e aprender podem ser feitos em casa, na rua, em lugares inusitados, e não estão mais limitados à sala de aula. Para os Parâmetros Curriculares Nacionais (PCNs), "a sociedade, de modo geral, está constantemente se beneficiando dos progressos da tecnologia sem, muitas vezes, ter consciência disso". Com as diversas transformações tecnológicas, o acesso às informações tem mudado a sala de aula e exigido novas posturas dos professores, sendo necessária uma maneira moderna de ensino para que o desempenho acadêmico dos estudantes nas ciências melhore em todas as instituições. 
A ciência e o método de ensino são dinâmicos, novas descobertas surgem a cada dia, e só poderemos nos beneficiar desse desenvolvimento quando estivermos conectados com o mundo através das Tecnologias da Informação e Comunicação (TICs), que admitem "pensar", "agir", "conviver" e "aprender" através de meios como a internet e o computador. As TICs são definidas por Tavares, Souza e Correia (2013) como "um conjunto de recursos tecnológicos que podem proporcionar comunicação e/ou automação de diversos tipos de processos em diversas áreas e principalmente no ensino e na pesquisa".

Muito se pensa que a Química é a disciplina que "aterroriza" somente alunos do ensino fundamental; porém, é cada vez mais comum esse quadro também no ensino superior, pois os alunos já trazem uma carga grande de dificuldades no aprendizado, não só da Química, mas das ciências de maneira geral. Cabe aos professores, então, traçar rotas alternativas para que esse cenário mude e o aprendizado se torne mais efetivo.

A disciplina de Bioquímica é oferecida no sétimo período do curso de Licenciatura em Química do Instituto Federal Goiano, campus Morrinhos, Goiás, e a ementa trata de assuntos como: estrutura e propriedades da água; aminoácidos; peptídeos; proteinas; ácidos nucleicos; lipídeos e vitaminas. $\mathrm{O}$ primeiro tema abordado é muito importante, pois abre as portas para os demais, visto que trata das interações que ocorrem na molécula de água, as ligações de hidrogênio, e da importância dessas para os vários sistemas biológicos, principalmente as proteínas. Devido à complexidade química e estrutural dessas biomoléculas e à dificuldade que os alunos tinham em visualizar sua formação e estrutura tridimensional, foi implementada uma metodologia de ensino com o uso da pesquisa e das TICs (internet, softwares e notebooks), em sala de aula, numa tentativa de melhorar o aprendizado e incentivar o aluno a procurar suas próprias fontes de estudos através dos dispositivos tecnológicos disponíveis.

Entendendo primeiramente a importância da formação de ligações de hidrogênio e outras interações intermoleculares em sistemas biológicos, foi possível aprofundar o tema proteínas com mais facilidade, uma vez que os alunos precisavam aprimorar e fixar os conceitos de maneira mais sólida e crítica. Entendeu-se que a construção desse conhecimento deveria consistir na participação real do aluno como pesquisador e na sua interação com os colegas e as ferramentas tecnológicas. A escolha das proteínas para esse estudo deu-se devido à grande curiosidade e ao interesse dos alunos por esse tema, por estar muito presente no dia a dia de todos. Já no primeiro dia de aula, quando a ementa do curso é passada aos alunos, eles são informados de que uma das atividades da disciplina é a escolha, por cada um deles, de uma proteína que tenha interesse em estudar; nesse momento, percebem-se a euforia e o interesse dos alunos sobre o tema.

A metodologia usada baseia-se em: 1) Explanação teórica sobre o tema com o uso de datashow e apresentação de slides; 2) Introdução ao estudo e manipulação, via internet, do maior banco de dados de armazenamento de proteínas, o PDB (do inglês Protein Data Bank), no qual é possível fazer pesquisa e obter informações sobre proteínas sintetizadas em todo o mundo; 3) Pesquisa (no PDB e em artigos científicos) e escolha, por cada aluno, individualmente, de uma proteína (ou enzima) de seu interesse para um estudo mais aprofundado, e posterior apresentação de um seminário sobre a biomolécula escolhida; 4) Pesquisa, estudo e download do programa de computador Chimera, usado como ferramenta de estudo, manipulação e visualização de moléculas e principalmente biomoléculas; 5) Apresentação do seminário em datashow, utilizando o programa Chimera, e discussão dos alunos sobre a pesquisa realizada.

Durante todo o curso de Bioquímica, o uso da pesquisa e das TICs como ferramentas de estudo e aprendizagem é incentivado. No início do semestre uma aula é dedicada à explicação e à demonstração on-line de busca de artigos científicos em revistas nacionais e internacionais, sobre os temas abordados na disciplina. Como todos os alunos têm acesso à internet e dispõem de computadores tipo notebooks, tablets e smartphones, a pesquisa torna-se possível e continua fora da sala de aula, motivando os alunos a usarem a tecnologia em prol dos estudos. 
As dúvidas que surgem podem ser tiradas através de um e-mail fornecido no início do semestre, bem como durante as aulas. E atualmente o aplicativo de telefone celular, WhatsApp, também tem sido explorado como canal de comunicação da disciplina. A maioria dos questionamentos é feita através das tecnologias (e-mail ou celular), pois os alunos ainda sentem vergonha de fazer perguntas em sala de aula. Eles também solicitam sugestões sobre o trabalho de pesquisa a ser realizado. Um exemplo de um pedido de sugestão de um aluno: "Professora, segue em anexo o artigo que escolhi para a pesquisa sobre enzimas, poderia dar uma olhada e me dizer o que a senhora acha?". Uma dúvida enviada pelo aplicativo de celular foi: "Boa noite, professora, tem algum problema a proteína não ter um grupo prostético?". Outra dúvida enviada por e-mail sobre a instalação do programa Chimera: "Professora, estou com dificuldade em baixar o Chimera, a senhora pode me ajudar hoje à noite?". Todos os questionamentos são atendidos quase imediatamente, e procura-se sempre sanar as dúvidas e ajudar os alunos da melhor maneira possível.

Essa metodologia, voltada para a pesquisa e o uso das ferramentas tecnológicas, é muito proveitosa e importante para o entendimento do conteúdo abordado, pois os alunos tinham dificuldade em visualizar os níveis estruturais das biomoléculas (estruturas primária, secundária, terciária e quaternária) e, principalmente, a formação de alfa-hélice e beta-folha na estrutura secundária. Já tendo visto como se formam as ligações de hidrogênio, a visualização e o entendimento das estruturas das proteínas se tornaram mais fáceis.

Como programa Chimera ${ }^{1}$, foi possível entender e visualizar as interações intermoleculares (principalmente ligações de hidrogênio) responsáveis pela estrutura tridimensional das proteínas.

A Figura 1 mostra a estrutura tridimensional da hemoglobina, código do PDB 5NI1, e indica, no programa Chimera, como podem ser encontradas as ligações de hidrogênio presentes na proteína. $\mathrm{Na}$ sequência, a Figura 2 mostra as ligações de hidrogênio (linhas em azul) encontradas na estrutura da hemoglobina. Até então, os alunos pouco tinham ouvido falar sobre programas de computador que tornassem possível esse aprofundamento do conteúdo. A primeira reação deles foi de surpresa, curiosidade e interesse. Todos puderam instalar o Chimera em seus computadores e manipular a proteína escolhida. Colágeno, insulina humana, betalactoglobulina (proteína do soro do leite), hemoglobina (Figura 2), pepsina, queratina, entre outras, são exemplos de proteínas estudadas pelos alunos, que, através da pesquisa em artigos científicos, livros, banco de dados de proteínas - PDB e outras fontes, produziram um texto, de maneira individual, abordando os principais aspectos da proteína de interesse: importância, função biológica e aspectos estruturais. Esse texto foi entregue no ato da apresentação oral do trabalho, em forma de seminário, usando o notebook e o datashow para a animação. $\mathrm{O}$ seminário consistiu em um resumo do que foi pesquisado e na exibição dos níveis estruturais da proteína (sequência de aminoácidos, presença de alfa-hélices e beta-folhas, interações intermoleculares e cadeias quaternárias, quando há) usando o programa Chimera.

Os resultados obtidos com essa metodologia foram bastante positivos, observados nas discussões feitas em sala de aula e também no nível da apresentação dos seminários realizados pelos alunos, que se mostraram muito empolgados com o uso das ferramentas tecnológicas e de pesquisa, nunca antes utilizadas por eles, o que resultou em um ótimo trabalho com um aprendizado satisfatório. O bom resultado dessa metodologia também foi comprovado pelas respostas dos alunos a um questionário (em anexo) aplicado ao final do trabalho de pesquisa.

Na pergunta 4 do questionário aplicado, os alunos foram assim indagados: "O que você achou do uso dos recursos tecnológicos (televisão, retroprojetor, programas de computador) durante a aula?”. Uma das respostas foi: "Muito interessante, pois o uso destas ferramentas ajuda no entendimento do conteúdo proposto".

A questão 7 perguntava: "Você tinha conhecimento do banco de dados PDB? Não ( ) $\operatorname{Sim}($ ). 


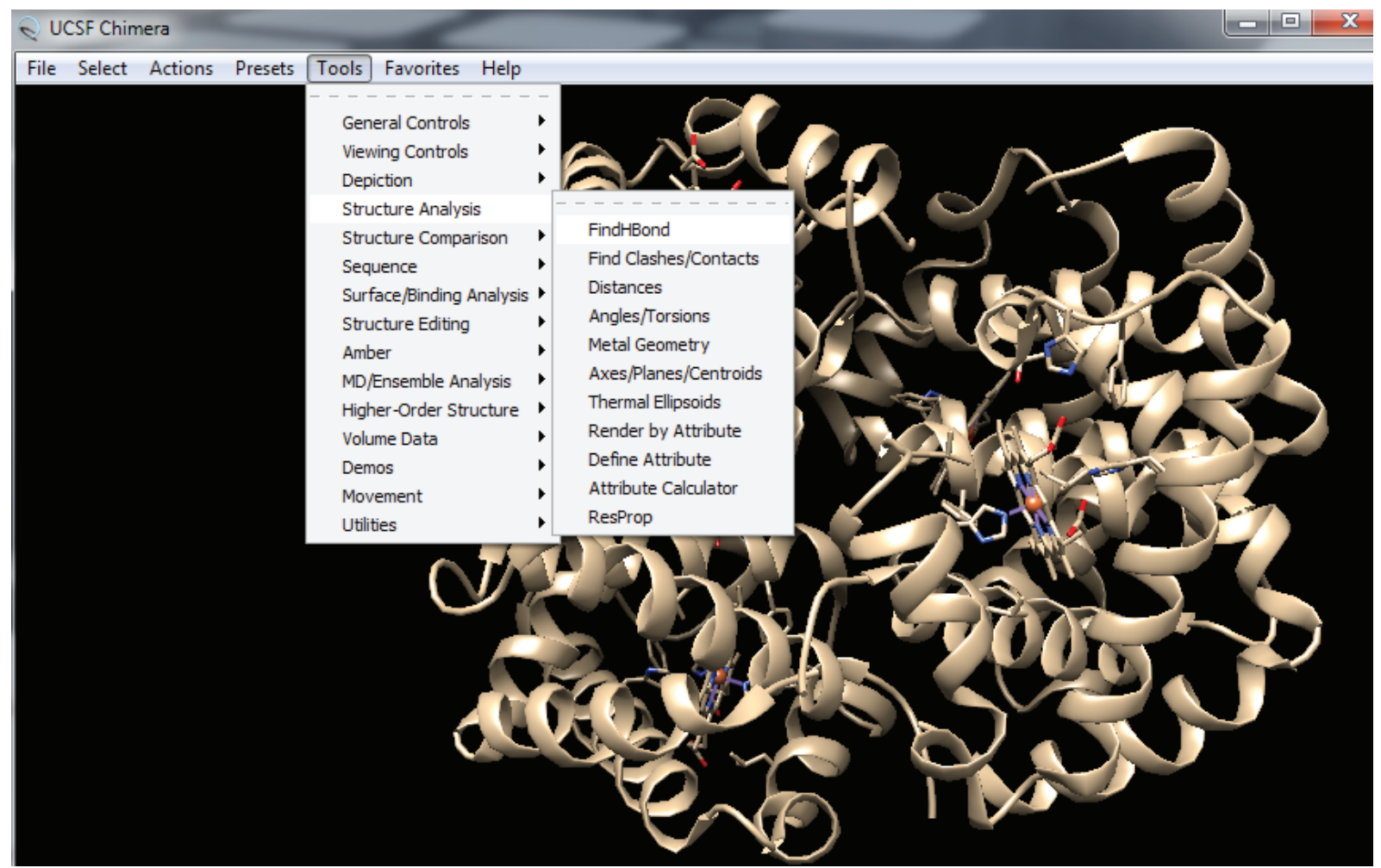

Figura 1 - Estrutura tridimensional da proteína hemoglobina (PDB 5NI1) representada pelo programa Chimera e indicação do caminho para encontrar as ligações de hidrogênio presentes.

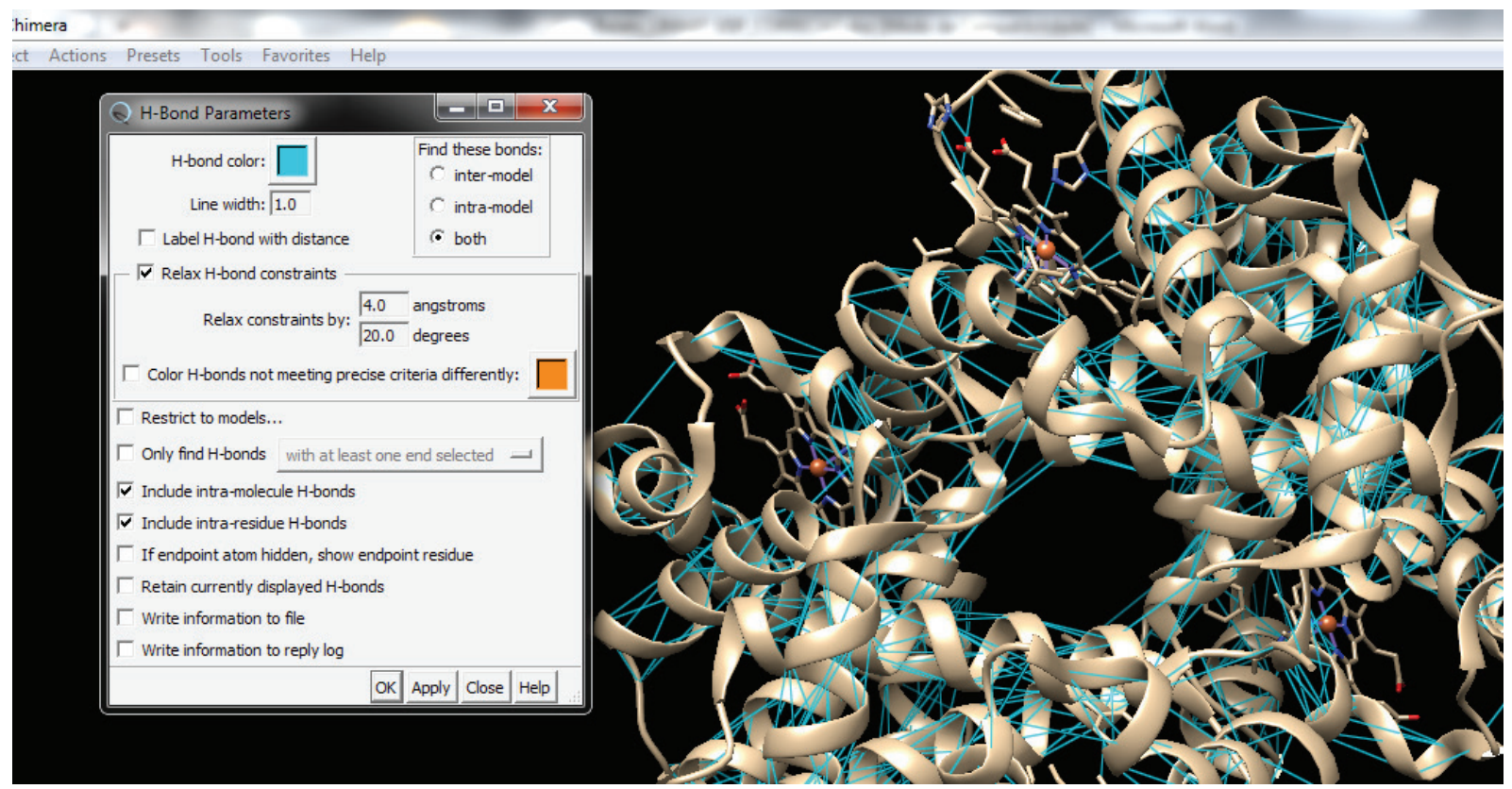

Figura 2 - Ligações de hidrogênio, representadas pelas linhas na cor azul, na estrutura da hemoglobina.

O que você achou desse recurso?". A resposta de outro aluno foi: "Não (x). Achei bastante interessante, porque agora sei onde encontrar proteínas que podem ser importantes para algum tipo de pesquisa, dentre outras utilizações, pois o site é bem completo". Analisando as respostas dos alunos ao questionário, observa-se que cerca de 90\% deles obtiveram um bom aproveitamento da metodologia empregada, e pode-se concluir que o uso das TICs, associadas à pesquisa, no ensino superior de Química e Bioquímica, é uma boa alternativa de melhoria na maneira de ensinar e no aprendizado dos alunos. 


\section{Agradecimentos}

Agradecimentos à Capes pelo apoio financeiro na implantação do projeto Life (Laboratório Interdisciplinar de Formação de Educadores) no IF Goiano, campus Morrinhos.

\section{Nota}

1 Disponível de maneira gratuita em: $<$ https://www. cgl.ucsf.edu/chimera/download.html $>$.

\section{Referências Bibliográficas}

ANDRADE, A. P. R. O Uso das Tecnologias na Educação: Computador e Internet. Monografia (Licenciatura em Biologia a Distância), Consórcio Setentrional de Educação a Distância, Universidade de Brasília, Universidade Estadual de Goiás, 2011. Disponível em: <http:// bdm.unb.br/bitstream/10483/1770/1/2011_AnaPaulaRochadeAndrade.pdf $>$. Acessado em 7 maio 2017.

BENITE, A. M. C. \& BENITE, C. R. M. "O Computador no Ensino de Química: Impressões Versus Realidade. Em Foco as Escolas Públicas da Baixada Fluminense". Ens. Pesqui. Educ. Ciênc. Belo Horizonte, vol. 10, n. 2, pp. 320-339, jul. 2008. Disponível em: $<$ http://www.scielo.br/scielo.php?script=sci_arttext\&pid=S1983-21172008000200320\&lng=en\&nrm=iso >. Acessado em 7 maio 2017.

BRASIL, Secretaria de Educação Fundamental. Parâmetros Curriculares Nacionais: Terceiro e Quarto Ciclos do Ensino Fundamental. Brasília: MEC/SEF, 1998.

BERMAN, H. M.; WESTBROOK, J.; FENG, Z.; GILLILAND, G.; BHAT, T. N.; WEISSIG, H.; SHINDYALOV, I. N. \& BOURNE, P. E. "The Protein Data Bank". Nucleic Acids Research, vol. 28, pp. 235242, 2000 .

KOLA, J. A. "Effective Teaching and Learning in Science Education through Information and Comunication Technology (ICT)". Fournal of Research \& Method in Education, vol. 2, n. 5, pp. 43-47, 2013.

PETTERSEN, E. F.; GODDARD, T. D.; HUANG, C. C.; GOUCH, G. S.; GREENBLATT, D. M.; MENG, E. C.; FERRIN, T. E. "UCSF Chimera: a Visualization System for Exploratory Research and Analysis". Fournal of Computational Chemistry, vol. 25, n. 13, pp. 1605-12, 2004.

TAVARES, R; SOUZA, R. O. \& CORREIA, A. O. "Um Estudo sobre a 'TIC' e o Ensino da Química". Revista Geintec, São Cristóvão/SE, vol. 3, n. 5, pp. 155-167, 2013. 


\title{
ANEXO
}

\section{INSTITUTO FEDERAL DE EDUCAÇÃO, CIÊNCIA E TECNOLOGIA GOIANO CAMPUS MORRINHOS}

\author{
Disciplina: Bioquímica \\ Professora: Dra. Emmanuela Ferreira de Lima \\ Questionário para alunos do $7^{\circ}$ período do curso de Licenciatura em Química \\ Avaliação da aula Proteínas/enzimas
}

Sexo: FEM. ( ) MASC. ( ) IDADE: ( )

1. Na sua opinião, a aula sobre as proteínas/enzimas foi proveitosa? Não ( ) Sim ( ) Por quê?

2. Você conseguiu entender a importância do tema estudado no seu dia a dia? Não ( ) Sim ( ). Justifique sua resposta.

3. Qual a sua opinião sobre a metodologia aplicada para o aprendizado do tema proteínas/enzimas?

4. O que você achou do uso dos recursos tecnológicos (televisão, retroprojetor, programas de computador) durante a aula?

5. Você achou que o tema estudado ficou mais interessante após essa aula com a utilização dos recursos tecnológicos? Não ( ) Sim ( ) Por quê??

6. Você sabia da existência de programas de computador voltados para a Química e Bioquímica, como o Chimera usado na aula? $\mathrm{O}$ que você achou desse recurso?

7. Você tinha conhecimento do banco de dados PDB? Não ( ) Sim ( ). O que você achou desse recurso?

8. Como foi o seu entendimento do tema considerando-se o uso de recursos tecnológicos? Restaram dúvidas sobre o tema? Justifique.

Muito obrigada pela sua contribuição! 